\title{
DAMPAK PENINGKATAN KONSUMSI PRODUK PERIKANAN TERHADAP PEREKONOMIAN NASIONAL
}

\author{
Tajerin ${ }^{1}$ \\ ${ }^{1}$ Peneliti pada Balai Besar Riset Sosial Ekonomi Kelautan dan Perikanan \\ JI. KS. Tubun Petamburan VI, Jakarta 10260 \\ Telp. 021 53650162/Fax. 02153650159
}

\begin{abstract}
ABSTRAK
Upaya pemerintah untuk meningkatkan konsumsi rumah tangga khususnya pada produk perikanan merupakan langkah penting dan strategis, terkait dengan peningkatan peran pasar dalam negeri dalam mengatasi tekanan krisis keuangan global yang sedang melanda Indonesia dewasa ini. Kajian bertujuan untuk menganalisis dampak peningkatan konsumsi rumah tangga pada produk perikanan terhadap perekonomian nasional. Kajian ini menggunakan data sekunder Tabel Input-Output 2005, Badan Pusat Statistik (BPS). Hasil analisis menunjukkan bahwa peningkatan konsumsi rumah tangga pada produk perikanan sebesar $11,54 \%$ akan berdampak meningkatkan output perekonomian sebesar Rp.10.031.490, pendapatan rumah tangga sebesar Rp.1.166.463 dan penyerapan tenaga kerja sebanyak 151.133 orang. Pemerintah hendaknya dapat mengimplementasi semua kebijakan dan program peningkatan konsumsi ikan dengan lebih sungguh-sungguh dan konsisten, sehingga konsumsi ikan per kapita per tahun dapat lebih ditingkatkan lagi. Di samping berdampak positif terhadap perekonomian, upaya peningkatan peran pasar domestik ini terkait dengan upaya untuk keluar dari tekanan krisis keuangan global.
\end{abstract}

Kata Kunci: Dampak Ekonomi, Ekonomi Rumah Tangga, Konsumsi, Produk Perikanan, Pemasaran.

\section{Abstract: Impact of the Increase in the Fisheries Product Consumption to National Economy. By: Tajerin.}

Increasing household consumption especially for fisheries sectors' product is an urgent and strategic government effort, since it is heavily linked to the goal of nullifying the threat of the recent global financial crisis through an effective role of domestic marketing. For that purpose, this research is aimed at analyzing the depth of the economic impact of raising household domestic consumption of fisheries sectors toward the Indonesian Economy, using Input Output analysis with secondary data (2005 I-O Table) acquired from BPS. Results showed that an $11.54 \%$ raise in household consumption of fisheries sectors produce, could impact on a Rp. 10,031,490 increase in the total output, a Rp.1,166,463 increase in household income, and a 151,133 increase in new labor absorption. Thus, our government should implement every possible policy and program that increase fish consumption whole-heartedly and consistently, so that the annual per capita fish consumption could be pushed forward, since it is positively affecting the whole economy as well as it is importantly linked to the effort of getting out of the pressure of the global financial crisis.

Keywords: Economic Impact, Household Economic, Consumption, Fisheries Product, Marketing 


\section{PENDAHULUAN}

Pada bulan September 2008, sebanyak 189 negara anggota Perserikatan BangsaBangsa (PBB) termasuk Indonesia menyetujui delapan butir Millenium Development Goals (MDGs), yaitu komitmen untuk mencapai kemajuan yang nyata dalam upaya pengentasan kemiskinan dan mencapai tujuan pembangunan manusia lainnya pada tahun 2015. Fokus pertama dari MDGs adalah menyangkut masalah kemiskinan dan kelaparan yang parah. Dua target yang ingin dicapai adalah (1) mengurangi hingga setengah jumlah orang yang hidup dengan pendapatan kurang dari \$1 per hari; dan (2) mengurangi hingga setengah jumlah orang yang kelaparan (Todaro and Smith, 2009).

Berkaitan dengan program MDGs tersebut, tujuan pembangunan dalam rangka pertumbuhan sosio ekonomi suatu negara diharapkan berorientasi pada manusia dan hak-haknya. Salah satu ukuran keberhasilannya dapat dilihat berdasarkan Indeks Pembangunan Manusia (Human Development Index - HDI) dengan tiga indeks turunannya, yaitu Indeks Kesehatan, Indeks Pendidikan dan Indeks Daya Beli (Muhammad, 2003; UNDP, 2004). Dua dari tiga indeks keberhasilan HDI (indeks kesehatan dan indeks pendidikan) berhubungan langsung dengan kualitas (mutu) pangan yang dikonsumsi oleh masyarakat suatu negara, yakni: indeks kesehatan dan indeks pendidikan (UNDP, 2004). Konsumsi pangan yang berkualitas tinggi dari sumber hewani ikan secara langsung akan berhubungan dengan kondisi kesehatan masyarakat dan kemampuan otak menjadi lebih baik, sehingga berdampak terhadap keberhasilan pendidikannya. Oleh karena itu, tingkat konsumsi ikan per kapita menjadi sangat penting dan perlu mendapatkan perhatian dan dukungan berbagai pihak terkait.

Departemen Kelautan dan Perikanan (DKP) telah menetapkan program peningkatan konsumsi ikan sebagai langkah strategis menuju Indonesia yang lebih maju. Upaya yang dilakukan antara lain adalah kampanye gemar makan ikan sebagai makanan yang menyehatkan, mencerdaskan dan menguatkan terus dilakukan dengan berbagai pendekatan dan media penyampaian, sehingga lebih meningkatkan konsumsi ikan masyarakat. Program peningkatan konsumsi ikan tersebut belum mampu mendorong konsumsi ikan per kapita Indonesia secara signifikan, karena bila dibandingkan dengan negara tetangga seperti Malaysia, konsumsi ikan per kapita Indonesia masih tergolong relatif rendah. Sebagai contoh, pada tahun 2003 konsumsi ikan masyarakat Indonesia hanya sebesar 22,36 $\mathrm{kg} / \mathrm{kapita} /$ tahun atau hanya mengkonsumsi ikan 24,50 gram (kurang dari satu ons) setiap hari per orang, sementara konsumsi ikan per kapita Malaysia telah mencapai $45 \mathrm{~kg} / \mathrm{kapita} / \mathrm{tahun} \mathrm{(DKP,} \mathrm{2005a).}$ Perkembangan konsumsi ikan per kapita secara nasional selama periode tahun 2000 2005 mengalami peningkatan sebesar 6,37\%, yaitu dari $21,57 \mathrm{~kg} / \mathrm{kapita} / \mathrm{tahun}$ pada tahun 2000 menjadi 28,69 kg/kapita/tahun pada tahun 2005 (DKP, 2005a).

Meskipun demikian, rendahnya konsumsi ikan di Indonesia tersebut tidak serta merta dijadikan alasan untuk menyatakan bahwa DKP telah gagal dalam meningkatkan konsumsi ikan nasional. Upaya peningkatan konsumsi ikan pada tingkat rumah tangga dalam pelaksanaan tidak mudah dan sangat terkait dengan budaya masyarakat, program dan kebijakan yang selama ini kurang kondusif (DKP, 2006). Oleh karena itu, DKP secara intensif memberikan pemahaman akan pentingnya mengkonsumsi ikan, di samping terus meningkatkan dukungan dari instansi terkait lainnya hingga tercapai sasaran tingkat konsumsi ikan per kapita pada tahun 2009 sebesar $32 \mathrm{~kg} / \mathrm{kapita} / \mathrm{tahun}$ sesuai yang ditetapkan pada Rencana Strategis Pembangunan Kelautan dan Perikanan tahun 2005-2009 (DKP, 2005b). 
Tekad kuat dari pemerintah untuk meningkatkan konsumsi ikan tersebut, di samping karena langkah yang penting, juga merupakan langkah strategis khususnya terkait dengan semangat untuk meningkatkan dan mengembangkan kekuatan pasar domestik atas produk yang dihasilkan di dalam negeri termasuk produk ikan. Terlebih lagi bila dikaitkan dengan semakin kuatnya tekanan dampak krisis keuangan global yang dirasakan bangsa Indonesia dewasa ini. Selain itu, upaya peningkatan konsumsi ikan dapat berarti mendorong produksi ikan di dalam negeri yang harus lebih tinggi lagi. Sebagai contoh, jika diasumsikan jumlah penduduk Indonesia saat ini mencapai 220 juta jiwa dan peningkatan konsumsi ikan sekitar 2 kg per kapita, maka dibutuhkan tambahan produksi ikan untuk memenuhi kebutuhan dalam negeri mencapai sebesar 440 juta kg atau 440 ribu ton. Pada gilirannya dengan meningkatkan konsumsi ikan dan produksi tersebut berarti pula meningkatkan kesejahteraan masyarakat nelayan dan pembudidaya ikan (DKP, 2006).

Kajian ini dilakukan dengan tujuan untuk menganalisis dampak peningkatan konsumsi rumah tangga pada produk hasil perikanan terhadap peningkatan output perekonomian, pendapatan rumah tangga dan penyerapan tenaga kerja. Hasil kajian diharapkan dapat berguna sebagai bahan masukan bagi para pembuat kebijakan (policy maker) terutama yang berkaitan dengan upaya meningkatkan konsumsi ikan di Indonesia.

\section{METODOLOGI}

\section{Data dan Sumber Data}

Untuk dapat merekam dampak peningkatan konsumsi rumah tangga terutama pada produk perikanan, digunakan data sekunder dari buku Tabel Input-Ouput (IO) Tahun 2005 yang disusun oleh Badan Pusat Statistik (2007) menurut klasifikasi matrik 175 x 175 sektor. Tabel I-O yang digunakan merupakan Tabel I-O transaksi domestik atas dasar harga produsen, dimana setiap nilai transaksi hanya mencakup barang dan jasa domestik dan dinilai atas dasar harga produsen dalam satuan jutaan rupiah. Dalam kajian ini, tabel I-O diklasifikasikan kembali sesuai dengan kepentingan analisis dengan cara melakukan agregasi beberapa sektor sehingga menjadi klasifikasi matriks $9 \times 9$ sektor, seperti tertera pada Tabel 1.

\section{Tabel1. Pengklasifikasian Sektor dari Tabel Input-Output Dampak Peningkatan Konsumsi Produk Perikanan Indonesia.}

Table 1. Sectors Classification of Input-Output Table of the Impact of the Increased in Indonesian Fisheries Product Consumption.

\begin{tabular}{ccc}
\hline $\begin{array}{c}\text { Sektor/ } \\
\text { Sector }\end{array}$ & \multicolumn{1}{c}{$\begin{array}{c}\text { Deskripsi/ } \\
\text { Description }\end{array}$} & $\begin{array}{c}\text { Sektor-Sektor dalam Tabel Input-Output/ } \\
\text { Sectors within Input-Output Table }\end{array}$ \\
\hline 1. & $\begin{array}{c}\text { Pertanian non perikanan/ } \\
\text { Non Fisheries Agriculture }\end{array}$ & $1-30$ \\
& $\begin{array}{l}\text { Perikanan Primer/ Primary Fisheries: } \\
\text { 2. Perikanan laut dan hasil perairan laut lainnya/ }\end{array}$ & $31 ; 33 \mathrm{~L}^{*)}$ \\
3. & $\begin{array}{c}\text { Marine fisheries and after marine products } \\
\text { Inland Fisheries and after marine products }\end{array}$ & $\left.32 ; 33 \mathrm{~L}^{* *}\right)$ \\
4. & $35-48$ \\
\hline
\end{tabular}




\section{Lanjutan Table 1/Continue Table 1}

\begin{tabular}{|c|c|c|}
\hline $\begin{array}{l}\text { Sektor/ } \\
\text { Sector }\end{array}$ & $\begin{array}{l}\text { Deskripsi// } \\
\text { Deskription }\end{array}$ & $\begin{array}{l}\text { Sektor-Sektor dalam Tabel Input-Output/ } \\
\text { Sectors within Input-Output Table }\end{array}$ \\
\hline & Perikanan Sekunder/ Secondary Fisheries: & \\
\hline 5. & $\begin{array}{l}\text { - Industri pengeringan dan penggaraman ikan } \\
\text { dan biota perairan lainnyal Fish dried and } \\
\text { salted industries }\end{array}$ & 53 \\
\hline 6. & $\begin{array}{l}\text { - Industri pengolahan dan pengawetan ikan dan } \\
\text { biota perairan lainnya/Processed and preserved } \\
\text { fish industries }\end{array}$ & 54 \\
\hline 7. & $\begin{array}{l}\text { Industri pengolahan hasil pertanian non } \\
\text { perikanan/ Agriculture non fisheries processed } \\
\text { industries }\end{array}$ & $49-52 ; 55-93$ \\
\hline 8. & $\begin{array}{l}\text { Industri pengolahan lainnya/ Other processing } \\
\text { industries }\end{array}$ & $94-141$ \\
\hline 9. & Jasa-jasa dan lainnya/ Services and others & $34 ; 142-175$ \\
\hline
\end{tabular}

Keterangan/ Remaks:

*) Proporsi output sektor 33 (udang) untuk sektor 31 sebesar $54,5 \%$ berasal dari udang hasil tangkapan di laut pada tahun 2005 (DKP, 2007) / Output proportion of sector 33 (shrimp) for sector 31 is $54.5 \%$ from marine capture in 2005 (DKP, 2007).

**) Proporsi output sektor 33 (udang) untuk sektor 32 sebesar 60,98\% pada tahun 2005/ Output proportion of sector 33 (shrimp) for sector 32 is $60.98 \%$ from marine capture in 2005 (DKP, 2007).

\section{Metoda Analisis Data}

Dalam kajian analisis dampak peningkatan konsumsi produk perikanan di tingkat rumah tangga terhadap perekonomian nasional dilakukan dengan menggunakan pendekatan model Input-Output (I-O) berdasarkan analisis angka pengganda (multiplier analysis). Analisis dampak berdasarkan angka pengganda ini merupakan suatu analisis yang umum dilakukan dalam kerangka model I-O. Analisis ini dapat dikatakan sebagai salah satu kekuatan model I-O tersebut (Nazara, 2007). Secara umum, analisis dampak ini menggambarkan dampak dari perubahan permintaan akhir dalam Tabel I-O baik terhadap sektor itu sendiri maupun terhadap sektor lain serta perekonomian secara keseluruhan. Permintaan akhir tersebut terdiri dari sejumlah komponen yang diperoleh dari perhitungan Produk Domestik Bruto (PDB) berdasarkan pengeluaran yang dilakukan oleh semua pelaku ekonomi terhadap produk barang dan jasa final meliputi: (a) konsumsi rumah tangga; (b) Investasi; (c) pengeluaran pemerintah; (d) Ekspor; dan (e) impor (Nazara, 2007).

Analisis dampak ini sangat berguna sebagai alat analisis kebijakan yang ingin diambil pemerintah, misalnya untuk mengetahui berapa besar dampak peningkatan konsumsi pada satu sektor tertentu terhadap perekonomian secara keseluruhan. Analisis dampak ini juga tidak terlepas dari analisis pengganda (multiplier). Analisis multiplier merupakan gambaran awal dari analisis dampak. Analisis multiplier adalah kasus khusus dari analisis dampak untuk perubahan satu unit mata uang pada satu sektor terhadap perekonomian. Dalam kajian ini analisis dampak peningkatan konsumsi rumah tangga pada produk hasil perikanan dibatasi pada dampaknya terhadap peningkatan output perekonomian, pendapatan rumah tangga dan penyerapan 
tenaga kerja. Peningkatan konsumsi produk hasil perikanan tersebut, dalam kajian ini ditentukan sebesar $11,54 \%$. Penentuan besaran angka peningkatan konsumsi rumah tangga tersebut (sebesar 11,54\% untuk produk perikanan) dilakukan dengan mempertimbangkan selisih antara target konsumsi ikan per kapita per tahun 2009 (sebesar 32 kg/ kapita/tahun) dengan capaiannya pada tahun 2005 (sebesar 28,69 kg/kapita/tahun) (DKP, 2005a; DKP, 2005b).

Dengan menggunakan pendekatan model I-O, maka hasil analisis dampak baik terhadap peningkatan output perekonomian, pendapatan rumah tangga maupun penyerapan tenaga kerja secara relatif akan menghasilkan persentase perubahan (dampak) yang sama untuk setiap peningkatan/pengurangan permintaan akhir pada masing-masing dampak tersebut. Hal ini dimungkinkan karena berkaitan dengan "asumsi linieritas" yang diberlakukan dalam penggunaan analisis model I-O. Sehingga analisis dampak yang dilakukan terhadap ketiganya terikat dengan kondisi Matriks Kebalikan (Inverse) Leontief yang sama sebagai penggandanya masing-masing berupa output multiplier. (Nazara, 2007; Miller and Blair, 1985). Untuk menganalisis ketiga jenis dampak tersebut, berikut ini dijelaskan masing-masing analisis dampak tersebut (Nazara, 2007; Miller and Blair, 1985; PBB, 1988; Mangiri, 2000; Lahr and Dietzenbacher, 2001).

\section{Analisis Dampak Output Perekonomian}

Seperti yang telah diungkapkan sebelumnya bahwa analisis tentang dampak model I-O tidak terlepas dari analisis multiplier. Oleh karena itu, analisis dampak output perekonomian pun tidak terlepas dari analisis multiplier output. Untuk menganalisis hal ini, perlu diawali dengan melihat bentuk persamaan dari model I-O seperti berikut:

$A X+F=X$

$X-A X=F$

$$
(I-A) X=F \text {. }
$$

sehingga besarnya output dapat dihitung sebagai pengaruh induksi permintaan akhir, seperti:

$$
X=(I-A)^{-1} F
$$

dimana:

$X=$ Matriks total output berukuran $n \times 1 / A n$ $n \times 1$ total output matrix

$I=$ Matriks identitas berukuran $n \times n / A n n$ $x$ n identity matrix

$F=$ Matriks permintaan akhir berukuran $n \times 1 /$ An $\times 1$ final demand matrix

$A=$ Matriks koefisien input /teknis berukuran $n \times n / A n n \times n$ technical coefficient matrix

Matriks identitas berguna untuk memudahkan manipulasi matematis. Suatu matriks jika dikalikan dengan matriks identitas akan menghasilkan matriks itu sendiri. Persamaan tersebutlah menjadi inti dari model I-O, sedangkan $(I-A)^{-1}$ disebut Matriks Kebalikan (Inverse) Leontief berfungsi sebagai pengganda (output multiplier). Kenaikan permintaan akhir $(F)$ suatu sektor tidak hanya berpengaruh langsung terhadap kenaikan total output $(X)$ sektor itu sendiri tetapi juga sektor lainnya. Besar kecilnya dampak dari kenaikan total output akibat kenaikan permintaan akhir tergantung dari besar kecilnya pengganda $(I-A)^{-1}$. Jika dalam Persamaan (4) dimasukkan impor (M), maka persamaan tersebut menjadi:

$$
\begin{aligned}
& A X+F=X+M \\
& X=(I-A)^{-1}(F-M)
\end{aligned}
$$

Pada persamaan tersebut dengan ( $\mathrm{F}-\mathrm{M})$ tertentu tingkat output yang diperlukan dapat diestimasi. Namun jika inverse (I - A) yang digunakan, maka impor diperlakukan sebagai variabel eksogenus. Mengingat bahwa dalam A sendiri sudah termasuk komponen impor, maka untuk membersihkan matriks $A$ dari 
komponen impor maka harus digunakan rumus:

$$
X=\left(I-A^{d}\right)^{-1} F^{d}
$$

dimana:

$A^{d}=$ Matriks koefisien teknis tanpa transaksi dari komponen impor berukuran $\mathrm{n} \times \mathrm{n} /$ An $n \times n$ matrix of technical coefficient without import transaction components

$F^{d}=$ Matriks Permintaan Akhir domestik atau ( $F-M)$ yang berukuran $n \times 1 /$ An $n \times 1$ domestic final demand matrix (F-M)

Matriks $\left(I-A^{d}\right)^{-1}$ adalah matriks pengganda yang sangat cocok digunakan untuk mengukur perubahan output domestik, akibat terjadinya perubahan pada permintaan akhir domestik.

Analisis dampak output perekonomian akibat perubahan permintaan akhir dapat ditunjukkan pada rumusan berikut:

$$
\Delta X=(I-A)^{-1} \Delta F \text {. }
$$

dimana $\Delta X$ menunjukkan perubahan output perekonomian dan $\Delta F$ menunjukkan perubahan permintaan akhir. Sedangkan analisis dampak output pada Tabel I-O yang berguna untuk menganalisis perubahan output domestik dapat ditunjukkan persamaan berikut ini:

$$
\Delta X=\left(I-A^{d}\right)^{-1} \Delta F^{d}
$$

Dimana $\Delta X$ merupakan perubahan output domestik serta $\Delta F^{d}$ adalah perubahan permintaan output domestik, yang dalam kajian dengan peningkatan permintaan konsumsi rumah tangga sebesar $11,54 \%$ untuk sektor perikanan.

\section{Analisis Dampak Pendapatan}

Analisis dampak pendapatan rumah tangga merupakan salah satu analisis dampak yang sangat penting untuk dianalisis dari Tabel
I-O. Berdasarkan analisis ini akan dapat diketahui berapa besar tambahan pendapatan akibat dari penambahan permintaan akhir. Seperti yang diketahui, suatu perusahaan tidak hanya membeli bahan baku dari perusahaan lainnya, melainkan juga dari masyarakat, dalam bentuk tenaga kerja. Balas jasa dari tenaga kerja ini berupa upah dan gaji. Oleh karena itu, kenaikan output berpengaruh langsung terhadap kenaikan input primer atau nilai tambah bruto (NTB), demikian juga dengan tambahan kebutuhan tenaga kerja.

Komponen pendapatan, seperti diketahui merupakan salah satu unsur dari input primer atau NTB yaitu berupa upah dan gaji. Koefisien pendapatan merupakan rasio komponen upah dan gaji terhadap total input (atau total output). Mengingat adanya hubungan linier antara perubahan output dan perubahan pendapatan, maka jika permintaan akhir berubah, pendapatan pun akan berubah. Besar-kecilnya dampak terhadap pendapatan suatu sektor dan sektor-sektor lainnya bergantung pada pengganda pendapatan (income multiplier). Angka dampak pendapatan dirumuskan sebagai :

$$
M=\hat{V}\left(1-A^{d}\right)^{-1}
$$

dimana:

$$
\begin{aligned}
M= & \text { Matriks dampak pendapatan } \\
& \text { berukuran } \mathrm{n} \times \mathrm{n} / \text { An } n \times n \\
& \text { income impactmatrix } \\
\left(I-A^{d}\right)^{-1}= & \text { Matriks pengganda output } \\
& \text { total/Total output multiplier } \\
& \text { matrix } \\
\hat{V} \quad= & \text { Matriks koefisien pendapatan } \\
& \text { berukuran } \mathrm{n} \times \mathrm{n} / \text { An } n \times n \\
& \text { income coefficient matrix }
\end{aligned}
$$

Matriks $\hat{V}$ merupakan matriks diagonal yang berisi koefisien pendapatan yang merupakan hasil bagi nilai input primer upah dan gaji dibagi dengan total input. Dengan demikian, dampak pendapatan adalah perkalian matriks diagonal koefisien pendapatan dengan pengganda output. Dampak perubahan permintaan akhir 
terhadap perubahan pendapatan rumah tangga menjadi:

$$
\Delta M=\hat{V}\left(I-A^{d}\right)^{-1} \Delta \mathrm{F}^{\mathrm{d}}
$$

dimana:

$$
\begin{aligned}
\Delta M= & \text { Tambahan pendapata } \mathrm{n} / \\
& \text { Additional income } \\
\Delta F= & \text { Tambahan permintaan akhir / } \\
& \text { Additional final demand }
\end{aligned}
$$

Persamaan (11) tersebut menunjukkan analisis dampak terhadap pendapatan rumah tangga dimana persamaan itu mengukur berapa besar tambahan pendapatan akibat tambahan permintaan akhir khususnya pada komponen konsumsi rumah tangga pada sektor perikanan yang meningkat sebesar $11,54 \%$.

\section{Analisis Dampak Tenaga Kerja}

Angka dampak penyerapan tenaga kerja digunakan untuk melihat penambahan kesempatan kerja baru akibat peningkatan permintaan akhir di suatu sektor tertentu, dalam hal ini adalah akibat perubahan konsumsi rumah tangga pada sektor perikanan yang meningkat sebesar $11,54 \%$. Dampak penyerapan tenaga kerja dirumuskan sebagai berikut:

$$
E=\hat{L}\left(I-A^{d}\right)^{-1}
$$

dimana:

$E=$ Matriks dampak penyerapan tenaga kerja/ Labor absorption impact matrix

$\hat{\mathrm{L}}=$ Matriks koefisien tenaga kerja yaitu berisi rasio tenaga kerja terhadap total input tiap sektor. Matriks ini adalah matriks diagonal dengan komponennya diperoleh dengan:/ Labor coefficient matrix, a ratio of labor per each sector's total input, a diagonal matrix required by:

$$
\hat{\mathrm{L}}=\frac{\mathrm{TK}_{\mathrm{j}}}{\mathrm{X}_{\mathrm{j}}}
$$

dimana:

$$
\begin{aligned}
\mathrm{Tk}_{\mathrm{j}}= & \text { Jumlah tenaga kerja sektor } \mathrm{j} / \\
& \text { Sector's } \mathrm{j} \text { labor } \\
\mathrm{X}_{\mathrm{j}}= & \text { Total input sektor } \mathrm{j} / \text { Sector's } \mathrm{j} \\
& \text { total input }
\end{aligned}
$$

Perubahan jumlah tenaga kerja yang dibutuhkan karena perubahan permintaan akhir domestik tiap sektor dirumuskan sebagai:

$$
\Delta \mathrm{E}=\hat{\mathrm{L}}\left(\mathrm{I}-\mathrm{A}^{\mathrm{d}}\right)^{-1} \Delta \mathrm{F}^{\mathrm{d}}
$$

Persamaan tersebut menunjukkan berapa besar tambahan tenaga kerja akibat perubahan permintaan akhir. Hasil kajian ini menunjukkan adanya perubahan permintaan konsumsi rumah tangga yang meningkat sebesar $11,54 \%$ untuk sektor perikanan.

\section{HASIL DAN PEMBAHASAN}

Analisis dampak peningkatan konsumsi produk perikanan dilakukan dalam tiga tahapan, yaitu: Pertama, analisis dampak terhadap output perekonomian; Kedua, analisis dampak terhadap pendapatan rumah tangga; dan Ketiga, analisis dampak terhadap penyerapan tenaga kerja. Hasil analisis dan pembahasan dari masing-masing analisis tersebut disajikan sebagai berikut:

\subsection{Dampak Terhadap Output Perekonomian}

Hasil analisis dampak peningkatan permintaan konsumsi rumah tangga pada produk hasil perikanan sebesar $11,54 \%$ terhadap output perekonomian tertera pada Tabel 2, Gambar 1 dan Gambar 2.

Dari tabel dan gambar-gambar tersebut dapat diketahui bahwa peningkatan konsumsi rumah tangga pada produk hasil perikanan sebesar $11,54 \%$, secara nasional akan berdampak terhadap peningkatan kinerja output perekonomian Indonesia sebesar $5,1765 \%$ (Rp.10.031.490) dengan variasi 
untuk keseluruhan sektor berkisar antara Rp. $13.305 .000(0,0044 \%)$ hingga Rp. $3.190 .192(2,5192 \%)$, atau rata-rata meningkat sebesar Rp. 1.114.610 (0,5832\%). Dari dampak peningkatan konsumsi produk hasil perikanan terhadap output perekonomian Indonesia, sebagian besar $(98,53 \%)$ dimiliki oleh sektor perikanan yaitu dengan peningkatan output perekonomian sebesar $5,1765 \%$ atau sebesar Rp. 9.884.302.

Tabel2. Hasil Analisis Dampak Peningkatan Konsumsi Produk Perikanan Sebesar 11,54\% Terhadap Output Perekonomian Indonesia, 2005.

Table 2. Impact of Increasing Fisheries Product Consumption (11.54\%) to Indonesian Economic Output, 2005.

\begin{tabular}{|c|c|c|c|c|}
\hline \multirow[b]{2}{*}{ No } & \multirow[b]{2}{*}{ Sektor/Sector } & \multicolumn{2}{|c|}{ Output (Juta Rp./Rp. Million ) } & \multirow{2}{*}{$\begin{array}{c}\text { Perubahan } \\
\text { Nilai (Juta Rpl.) } \\
\text { Value Change } \\
\text { (Rp. Million) }\end{array}$} \\
\hline & & $\begin{array}{l}\text { Sebelum*)/ } \\
\text { Before }\end{array}$ & $\begin{array}{l}\text { Setelah } * *) / \\
\text { After }\end{array}$ & \\
\hline \multirow[t]{2}{*}{1} & $\begin{array}{l}\text { Pertanian non perikanan/ } \\
\text { Agriculture non fisheries }\end{array}$ & 299.015 .623 & 299.028 .928 & 13.305 \\
\hline & $\begin{array}{l}\text { Perikanan primer/Primary } \\
\text { fisheries }\end{array}$ & 293.469 .854 & 298.719.805 & 5.249 .951 \\
\hline 2 & Perikanan darat/Inland fisheries & 126.635 .614 & 129.825 .807 & 3.190 .192 \\
\hline 3 & Perikanan laut/Marine fisheries & 166.834 .239 & 168.893.998 & 2.059.759 \\
\hline \multirow[t]{2}{*}{4} & $\begin{array}{l}\text { Pertambangan dan } \\
\text { Penggalian/Minning and quarry }\end{array}$ & 71.457 .799 & 71.497 .077 & 39.278 \\
\hline & $\begin{array}{l}\text { Perikanan sekunder/Secondary } \\
\text { fisheries }\end{array}$ & 615.511 .648 & 620.146 .000 & 4.634.351 \\
\hline 5 & $\begin{array}{l}\text { Penggaraman Ikan/Dried and } \\
\text { salted processing industry }\end{array}$ & 339.530 .388 & 343.313 .116 & 3.782 .728 \\
\hline 6 & $\begin{array}{l}\text { Pengawetan Ikan/Processed and } \\
\text { preserved industry }\end{array}$ & 275.981 .260 & 276.832 .884 & 851.624 \\
\hline 7 & $\begin{array}{l}\text { Pertanian non } \\
\text { perikanan/Agriculture non } \\
\text { fisheries processing industry }\end{array}$ & 733.852 .070 & 733.871 .939 & 19.870 \\
\hline 8 & $\begin{array}{l}\text { Industri pengolahan lainnya/Other } \\
\text { processing industry }\end{array}$ & 423.367 .358 & 423.395 .340 & 27.982 \\
\hline 9 & $\begin{array}{l}\text { Jasa-jasa dan Lainnya/Service } \\
\text { and Other }\end{array}$ & 1.163.199.961 & 1.163.246.715 & 46.753 \\
\hline \multicolumn{2}{|c|}{$\begin{array}{l}\text { Jumlah sektor perikanan/Amount of } \\
\text { fisheries sector }\end{array}$} & 908.981 .502 & 918.865 .804 & 9.884 .302 \\
\hline \multicolumn{2}{|c|}{$\begin{array}{l}\text { Jumlah seluruh sektor/Amount of all } \\
\text { sector }\end{array}$} & 3.599.874.313 & 3.609 .905 .803 & 10.031 .490 \\
\hline \multicolumn{2}{|c|}{$\begin{array}{l}\text { Rata-rata seluruh sektor/Average of } \\
\text { all sector }\end{array}$} & 399.986 .035 & 401.100 .645 & 1.114 .610 \\
\hline
\end{tabular}

Sumber: Hasil Pengolahan Data Tabel Input-Output Tahun 2005.

Source: Data Processing Input-Output Table of 2005.

Keterangan/Remarks:

*) Kondisi sebelum dampak peningkatan konsumsi produk perikanan/Output before fisheries product consumption increasing impact

${ }^{* *}$ Kondisi setelah dampak peningkatan konsumsi produk perikanan sebesar 11,54\%/Output after fisheries product consumption increasing was $11.54 \%$ 


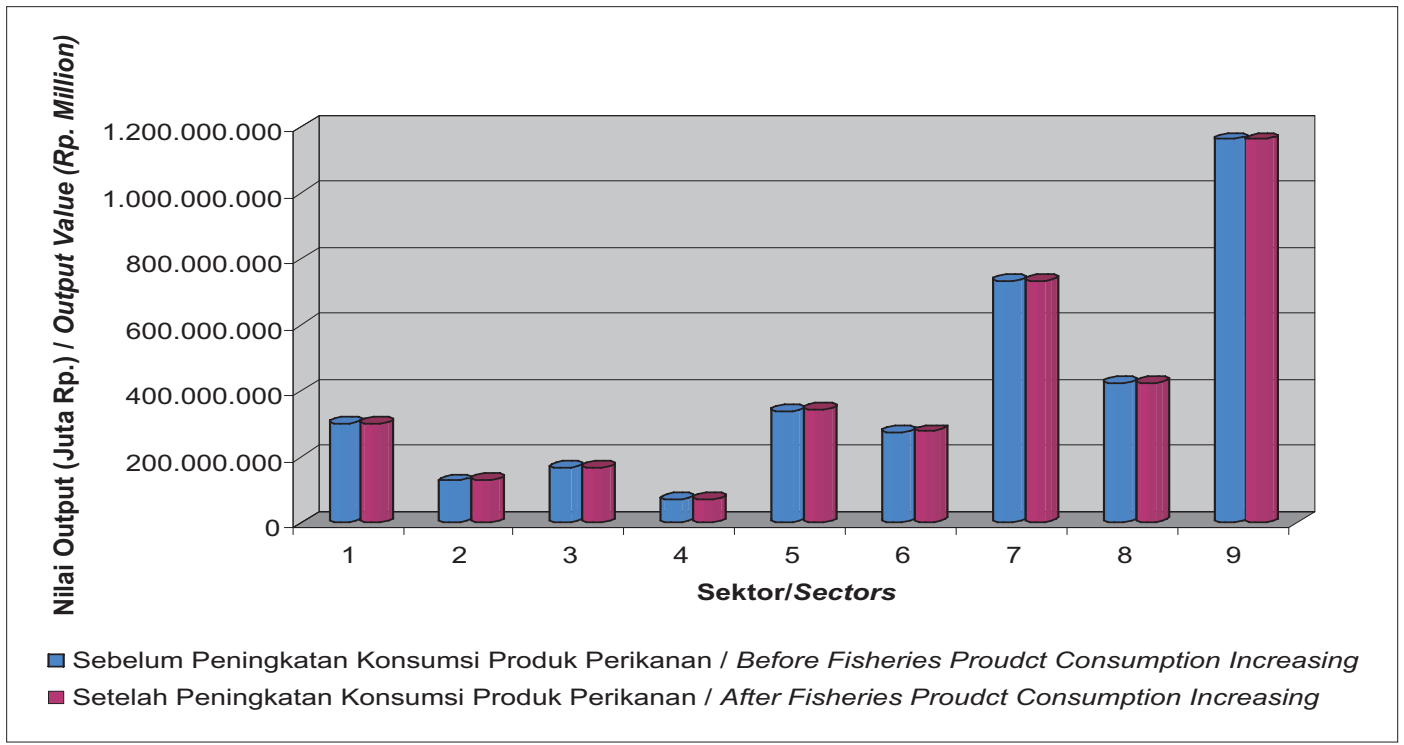

Gambar 1. Nilai Output Menurut Sektor pada Kondisi Sebelum dan Setelah Peningkatan Konsumsi Produk Perikanan 11,54\% di Indonesia, 2005 (Juta Rp. ).

Figure 1. Output Value of Sector at Before and After of the Increase Fisheries Product Consumption (11.54\%) in Indonesia, 2005 (Rp. Million).

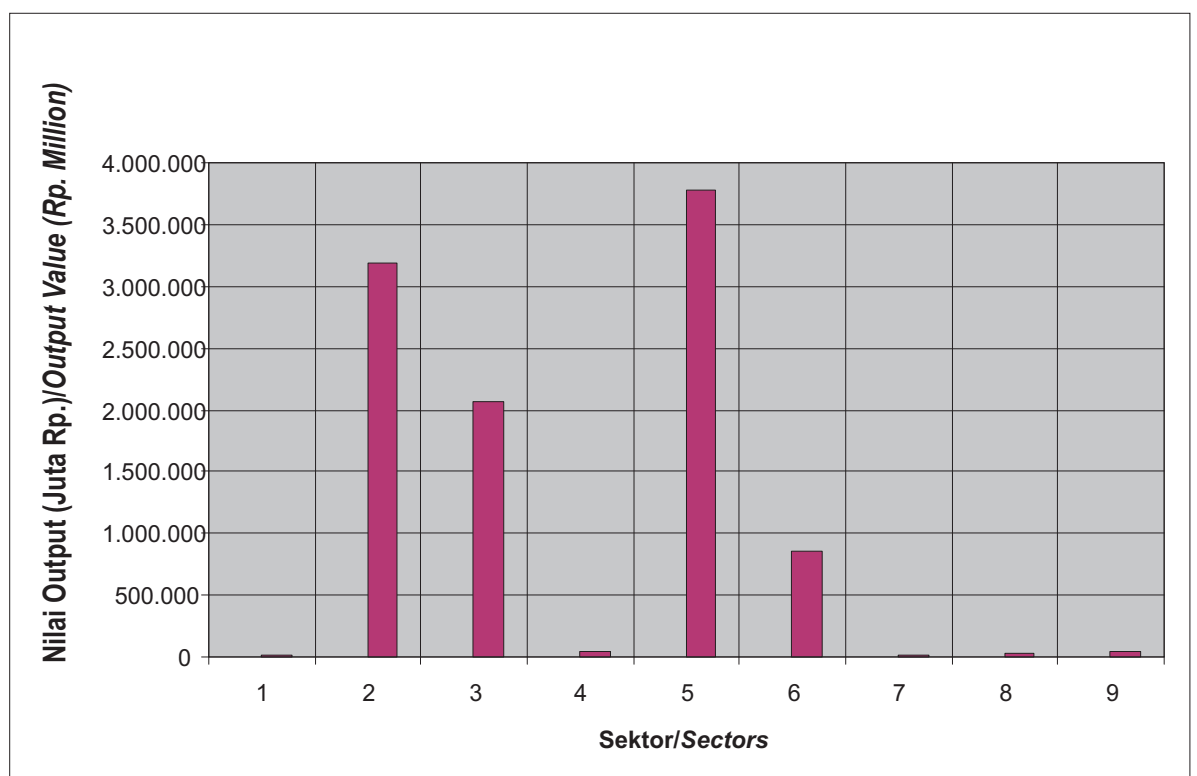

Gambar 2. Perubahan Nilai Output Menurut Sektor pada Kondisi Sebelum dan Setelah Peningkatan Konsumsi Produk Perikanan 11,54\% di Indonesia, 2005 (Juta Rp.).

Figure 2. Output Value Change of Sector at Before and After of the Increase Fisheries Product Consumption (11.54\%) in Indonesia (Rp. Million). 
Sedangkan sisanya sebesar 1,34\% dengan peningkatan output perekonomian sebesar 0,0628\% (Rp. 133.883.000) dimiliki oleh sektor lainnya dalam perekonomian Indonesia.

Selanjutnya bila dilihat berdasarkan bagian dari sektor perikanan, secara relatif dampak terhadap peningkatan output perekonomian yang diterima oleh perikanan primer dari peningkatan konsumsi rumah tangga pada produk hasil perikanan tersebut (meningkat sebesar Rp. 5.249.951.000 atau $3,7538 \%$ ) lebih besar dibandingkan dengan perikanan sekunder (meningkat sebesar Rp, 4.634.351.000 atau 1,4227\%). Pada perikanan primer, dampak tersebut secara relatif didominasi oleh peningkatan output perekonomian perikanan darat yaitu sebesar $2,5192 \%$ dengan nilai sebesar Rp. 3.190.192.000, sedangkan perikanan laut hanya meningkat sebesar $1,2346 \%$ dengan nilai sebesar Rp. 2.059.759.000. Sementara itu untuk perikanan sekunder, dampak tersebut secara relatif didominasi oleh peningkatan output perekonomian industri pengeringan dan penggaraman ikan dan biota perairan lainnya yaitu sebesar $1,1141 \%$ dengan nilai sebesar Rp. 3.782.728.000, sedangkan industri pengolahan dan pengawetan ikan dan biota perairan lainnya hanya meningkat sebesar Rp. 851.625.000.

\subsection{Dampak Terhadap Pendapatan Rumah Tangga}

Tabel 3, Gambar 3 dan 4 memperlihatkan hasil analisis dampak peningkatan permintaan konsumsi rumah tangga pada produk hasil perikanan sebesar $11,54 \%$ terhadap pendapatan rumah tangga. Secara nasional, konsumsi rumah tangga pada produk hasil perikanan yang meningkat sebesar $11,54 \%$ akan berdampak terhadap peningkatan pendapatan rumah tangga di Indonesia sebesar 5,2492\% (Rp. 1.166.463.000) dengan variasi untuk keseluruhan sektor berkisar

Tabel 3. Hasil Analisis Dampak Peningkatan Konsumsi Produk Perikanan Sebesar $11,54 \%$ Terhadap Pendapatan Rumah Tangga di Indonesia, 2005.

Table 3. Impact of the Fisheries Product Consumption Increased (11.54\%) to Household Income in Indonesia, 2005.

\begin{tabular}{|c|c|c|c|c|}
\hline \multirow{2}{*}{ No } & \multirow{2}{*}{ Sektor/Sector } & \multicolumn{2}{|c|}{$\begin{array}{c}\text { Pendapatan ( Juta Rp.)/ } \\
\text { Income (Rp. Million) }\end{array}$} & \multirow{2}{*}{$\begin{array}{c}\text { Perubahan } \\
\text { Nilai (Juta Rp.)/ } \\
\text { Value Change } \\
\text { (Rp. Million) }\end{array}$} \\
\hline & & $\begin{array}{l}\text { Sebelum*)/ }^{*} \\
\text { Before }\end{array}$ & $\begin{array}{l}\text { Setelah }^{* *} / \\
\text { After }\end{array}$ & \\
\hline \multirow[t]{2}{*}{1} & Pertanian non perikanan/ & 51.852 .864 & 51.855 .171 & 2.307 \\
\hline & Perikanan primer/Primary fisheries & 47.365.017 & 48.205 .922 & 840.905 \\
\hline 2 & Perikanan darat/Inland fisheries & 19.938.856 & 20.441 .154 & 502.298 \\
\hline 3 & Perikanan laut/Marine fisheries & 27.426 .161 & 27.764 .768 & 338.607 \\
\hline \multirow[t]{2}{*}{4} & $\begin{array}{l}\text { Pertambangan dan Penggalian/Minning } \\
\text { and quarry }\end{array}$ & 8.058 .332 & 8.062 .761 & 4.429 \\
\hline & $\begin{array}{l}\text { Perikanan sekunder/ Secondary } \\
\text { fisheries }\end{array}$ & 38.174 .633 & 38.479 .093 & 304.461 \\
\hline 5 & $\begin{array}{l}\text { Penggaraman lkan/Dried and salted } \\
\text { processing industry }\end{array}$ & 23.172 .602 & 23.430 .770 & 258.167 \\
\hline 6 & $\begin{array}{l}\text { Pengawetan Ikan/Processed and } \\
\text { preserved industry }\end{array}$ & 15.002 .030 & 15.048 .324 & 46.293 \\
\hline 7 & $\begin{array}{l}\text { Pertanian non perikanan/ Agriculture non } \\
\text { fisheries processing industry }\end{array}$ & 72.850 .508 & 72.852 .480 & 1.972 \\
\hline
\end{tabular}


Lanjutan tabel $3 /$ Continue table 3

\begin{tabular}{|c|c|c|c|c|}
\hline \multirow{2}{*}{ No } & \multirow{2}{*}{ Sektor/Sector } & \multicolumn{2}{|c|}{$\begin{array}{l}\text { Pendapatan ( Juta Rp.)/ } \\
\text { Income (Rp. Million) }\end{array}$} & \multirow{2}{*}{$\begin{array}{c}\text { Perubahan } \\
\text { Nilai (Juta Rp.)/ } \\
\text { Value Change } \\
\text { (Rp. Million) }\end{array}$} \\
\hline & & $\begin{array}{l}\text { Sebelum*/1 } \\
\text { Before }\end{array}$ & $\begin{array}{l}\text { Setelah }{ }^{* *)} / \\
\text { After }\end{array}$ & \\
\hline 8 & $\begin{array}{l}\text { Industri pengolahan lainnya/Other } \\
\text { processing industry }\end{array}$ & 48.473 .557 & 48.476 .761 & 3.204 \\
\hline 9 & Jasa-jasa dan Lainnya/Service and Other & 228.496 .804 & 228.505 .989 & 9.184 \\
\hline \multicolumn{2}{|c|}{ Jumlah sektor perikanan/ } & \\
\hline \multicolumn{4}{|c|}{ Amount of all sector } & 1.166 .463 \\
\hline $\begin{array}{l}\text { Rat } \\
\text { Ave }\end{array}$ & $\begin{array}{l}\text { a-rata seluruh sektorl } \\
\text { rage of all sector }\end{array}$ & 55.030 .191 & 55.159 .798 & 129.607 \\
\hline
\end{tabular}

Sumber: Hasil Pengolahan Data Tabel Input-Output Tahun 2005

Source: Data Procesing Input-Output Table of 2005.

Keterangan/Remarks:

*) Kondisi sebelum peningkatan konsumsi produk perikanan/Income before fisheries product consumption

${ }^{* *}$ ) Kondisi setelah peningkatan konsumsi produk perikanan sebesar $11,54 \% /$ Income after fisheries product consumption increasing was $11.54 \%$

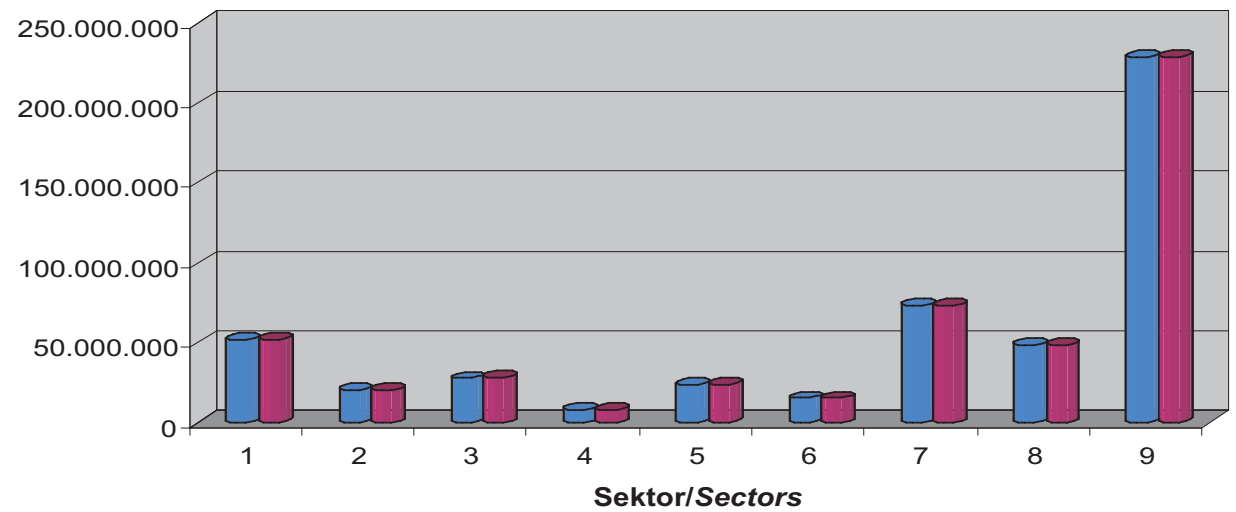

$\square$ Sebelum Peningkatan Konsumsi Produk Perikanan /Before Fisheries Proudct Consumption Increasing

- Setelah Peningkatan Konsumsi Produk Perikanan/After Fisheries Proudct Consumption Increasing

Gambar 3. Nilai Pendapatan Rumah Tangga Menurut Sektor pada Kondisi Sebelum dan Setelah Peningkatan Konsumsi Produk Perikanan 11,54\% di Indonesia, 2005.

Figure 3. Household Income Value of Sectors at Before and After of the Increase of Fisheries Product Consumption (11.54\%) in Indonesia, 2005. 


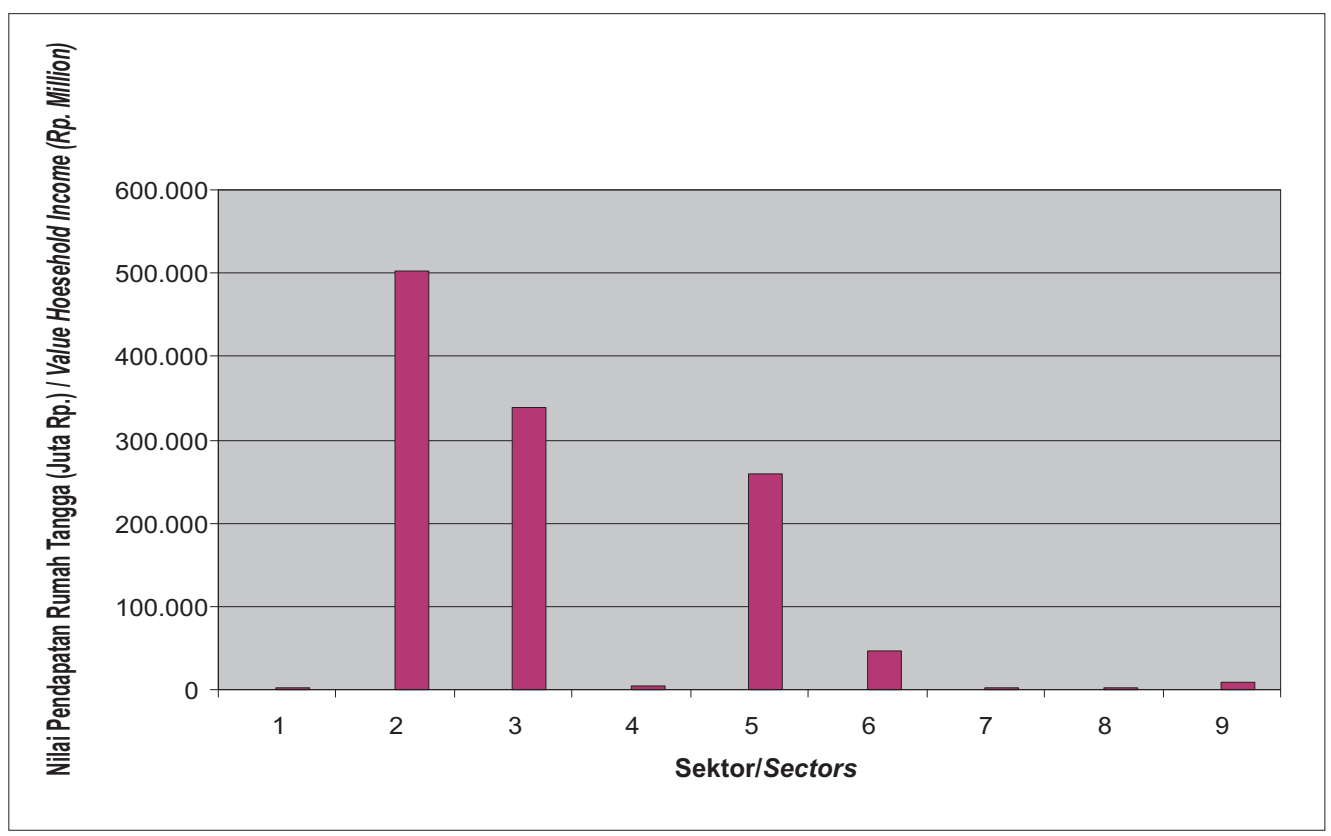

Gambar4. Perubahan Nilai Pendapatan Rumah Tangga Menurut Sektor Akibat Peningkatan Konsumsi Produk Perikanan 11,54\% di Indonesia, 2005 ( Juta Rp.).

Figure 4. Value Change of Household Income of Sectors as a Result of the Increase of Fisheries Product Consumption (11.54\%) in Indonesia, 2005 (Rp. Million).

antara Rp. 2.307 juta $(0,0044 \%)$ hingga Rp. $502.298 .000(2,5192 \%)$ atau rata-rata meningkat sebesar Rp. 129.607.000 $(0,5832 \%)$. Dari dampak peningkatan konsumsi secara nasional tersebut, sebagian besar $(98,19 \%)$ dimiliki oleh sektor perikanan yaitu dengan peningkatan pendapatan rumah tangga sebesar 5,1765\% (Rp. 1.145.366.000). Sedangkan sisanya sebesar $1,81 \%$ dengan peningkatan pendapatan rumah tangga sebesar 0,0628\% (Rp. 21.097.000) dimiliki oleh sektor lainnya dalam perekonomian Indonesia.

Bila dampak terhadap peningkatan pendapatan rumah tangga tersebut diamati dari bagian sektor perikanan, secara relatif dampak terhadap peningkatan pendapatan rumah tangga yang diterima oleh perikanan primer dari peningkatan konsumsi rumah tangga pada produk hasil perikanan tersebut (meningkat sebesar Rp. 840.905.000 atau
$3,7538 \%$ ) lebih besar dibandingkan dengan perikanan sekunder (meningkat sebesar $\mathrm{Rp}, 304.461 .000$ atau $1,4227 \%$ ). Untuk perikanan primer, dampak tersebut secara relatif didominasi oleh peningkatan pendapatan rumah tangga dari perikanan darat yaitu sebesar 2,5192\% dengan nilai sebesar Rp.502.298.000, sedangkan perikanan laut hanya meningkat sebesar $1,2346 \%$ dengan nilai sebesar Rp.338.607.000. Sementara itu pada perikanan sekunder, dampak tersebut secara relatif didominasi oleh peningkatan pendapatan rumah tangga dari industri pengeringan dan penggaraman ikan dan biota perairan lainnya yaitu sebesar $1,1141 \%$ dengan nilai sebesar Rp.258.167.000, sedangkan industri pengolahan dan pengawetan ikan dan biota perairan lainnya hanya meningkat sebesar $0,3086 \%$ dengan nilai sebesar Rp. 46.293 .000. 


\subsection{Dampak Terhadap Penyerapan Tenaga Kerja \\ Pada Tabel 4, Gambar 5 dan Gambar 6.} Dari Tabel 4, Gambar 5 dan Gambar 6 dapat diketahui bahwa peningkatan konsumsi rumah tangga pada produk hasil perikanan sebesar $11,54 \%$, secara nasional akan berdampak terhadap peningkatan pendapatan rumah tangga di Indonesia sebesar 5,2492\% (sebanyak 151.133 orang tenaga kerja)

Tabel 4. Hasil Analisis Dampak Peningkatan Konsumsi Produk Perikanan sebesar 11,54\% Terhadap Penyerapan Tenaga Kerja di Indonesia, 2005.

Table 4. Impact of the Increase of Fisheries Product Consumption (11.54\%) to Labor Absorption in Indonesia, 2005

\begin{tabular}{|c|c|c|c|}
\hline \multirow[t]{2}{*}{ Sektor/Sector } & \multicolumn{2}{|c|}{$\begin{array}{l}\text { Tenaga Kerja(Orang)/ } \\
\text { Employment (Man) }\end{array}$} & \multirow{2}{*}{$\begin{array}{l}\text { Perubahan Tenaga } \\
\text { Kerja (Orang)/ } \\
\text { Change of } \\
\text { Employment (Man) }\end{array}$} \\
\hline & $\begin{array}{l}\text { Sebelum*)/ } \\
\text { Before }\end{array}$ & $\begin{array}{l}\text { Setelah }{ }^{* *)} / \\
\text { After }\end{array}$ & \\
\hline $\begin{array}{l}\text { 1. Pertanian non perikanan/ } \\
\text { Agriculture non fisheries }\end{array}$ & 29.345 .741 & 29.347 .047 & 1.306 \\
\hline Perikanan primer/Primary fisheries & 9.579 .906 & 9.713.257 & 133.352 \\
\hline 2. Perikanan darat/Inland fisheries & 1.173 .673 & 1.203 .240 & 29.567 \\
\hline 3. Perikanan laut/Marine fisheries & 8.406 .233 & 8.510 .018 & 103.785 \\
\hline $\begin{array}{l}\text { 4. Pertambangan dan penggalian/ } \\
\text { Mining and quarrying }\end{array}$ & 159.737 & 159.825 & 88 \\
\hline Perikanan sekunder/Secondary fisheries & 2.047.188 & 2.062 .601 & 15.414 \\
\hline $\begin{array}{l}\text { 5. Industri pengeringan dan penggaraman } \\
\text { ikan/Fish dried and salted industries }\end{array}$ & 1.129.279 & 1.141 .861 & 12.581 \\
\hline $\begin{array}{l}\text { 6. Industri pengolahan dan pengawetan ikan/ } \\
\text { Fish processed and preserved industries }\end{array}$ & 917.908 & 920.741 & 2.832 \\
\hline $\begin{array}{l}\text { 7. Industri pengolahan hasil pertanian } \\
\text { non perikanan/Agriculture non fisheries } \\
\text { processing industries }\end{array}$ & 6.457 .040 & 6.457 .215 & 175 \\
\hline $\begin{array}{l}\text { 8. Industri pengolahan lainnya/ } \\
\text { Other processing industries }\end{array}$ & 1.401 .575 & 1.401 .668 & 93 \\
\hline 9. Jasa-jasa dan lainnya/Services and others & 17.588 .556 & 17.589 .263 & 707 \\
\hline $\begin{array}{l}\text { Jumlah sektor perikanan/ } \\
\text { Amount of fisheries sector }\end{array}$ & 11.627 .093 & 11.775 .859 & 148.765 \\
\hline $\begin{array}{l}\text { Jumlah seluruh sektorl } \\
\text { Amount of all sector }\end{array}$ & 66.579 .743 & 66.730 .876 & 151.133 \\
\hline $\begin{array}{l}\text { Rata-rata seluruh sektorl } \\
\text { Average of all sector }\end{array}$ & 7.397.749 & 7.414.542 & 16.793 \\
\hline
\end{tabular}

Sumber: Hasil Pengolahan Data Tabel Input-Output Tahun 2005.

Source: Data Processing Input-Output Table of 2005.

Keterangan/Remaks:

*) Kondisi sebelum peningkatan konsumsi produk perikanan/Labor before fisheries product consumption increasing.

${ }^{* *}$ ) Kondisi setelah peningkatan konsumsi produk perikanan sebesar $11,54 \% /$ Labor after fisheries product consumption increasing was $11.54 \%$. 


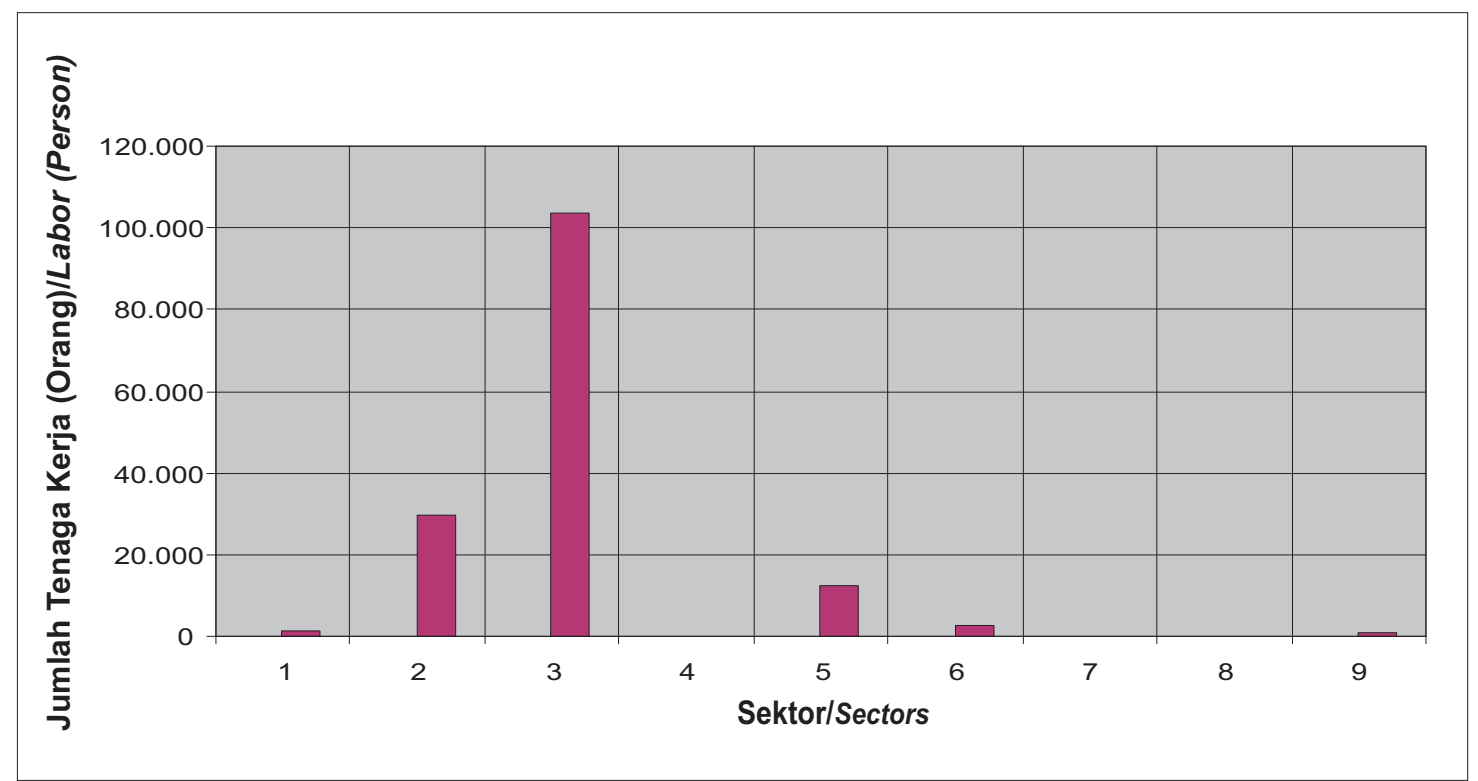

Gambar 5. Penyerapan Tenaga Kerja Menurut Sektor Akibat Peningkatan Konsumsi Produk Perikanan $11,54 \%$ di Indonesia, 2005 (Orang).

Figure 5. Labor Absorption of Sectors as a Result of the Increase of Fisheries Product Consumption (11.54\%) in Indonesia, 2005 (Person).

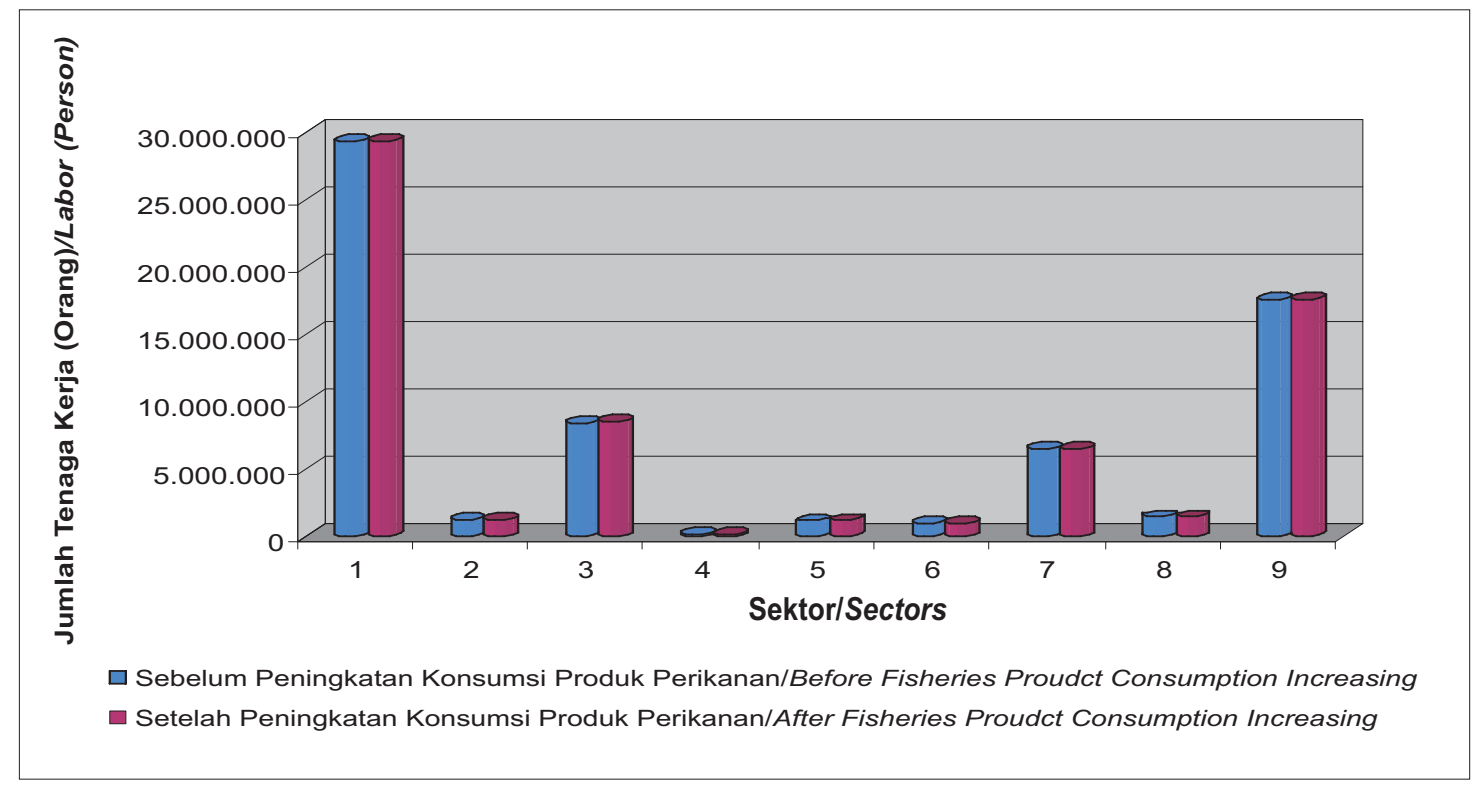

Gambar 6. Perubahan Penyerapan Tenaga Kerja Menurut Sektor Akibat Peningkatan Konsumsi Produk Perikanan 11,54\% di Indonesia, 2005 (Orang).

Figure 6. Labor Absorption Change of Sector as a Result of the Increase of Fisheries Product Consumption (11.54\%) in Indonesia, 2005 (Person). 
dengan variasi untuk keseluruhan sektor berkisar antara sebesar 0,0044\% dengan tambahan penyerapan tenaga kerja sebanyak 1.306 orang hingga 2,5192\% dengan tambahan penyerapan tenaga kerja sebanyak 29.567 orang, atau rata-rata meningkat sebesar $0,5832 \%$ dengan tambahan penyerapan tenaga kerja sebanyak 16.793 orang. Dari dampak peningkatan konsumsi secara nasional tersebut, sebagian besar $(98,19 \%)$ dimiliki oleh sektor perikanan yaitu dengan peningkatan penyerapan tenaga kerja sebesar $5,1765 \%$ (148.765 orang). Sedangkan sisanya sebesar $1,81 \%$ (sebanyak 2.368 orang tenaga kerja) dimiliki oleh sektor lainnya dalam perekonomian Indonesia.

Lebih lanjut bila dilihat berdasarkan bagian dari sektor perikanan, secara relatif dampak terhadap penyerapan tenaga kerja yang diterima oleh perikanan primer dari peningkatan konsumsi rumah tangga pada hasil perikanan tersebut (meningkat sebanyak 133.352 orang tenaga kerja atau 3,7538\%) lebih besar dibandingkan dengan perikanan sekunder (meningkat sebanyak 15.414 orang tenaga kerja atau $1,4227 \%$ ). Pada perikanan primer, dampak tersebut secara relatif didominasi oleh peningkatan penyerapan tenaga kerja dari perikanan darat yaitu sebesar 2,5192\% dengan tambahan penyerapan tenaga kerja sebanyak 29.567 orang, sedangkan perikanan laut hanya meningkat sebesar $1,2346 \%$ dengan tambahan penyerapan tenaga kerja sebanyak 103.785 orang. Sementara itu untuk perikanan sekunder, dampak tersebut secara relatif didominasi oleh peningkatan kinerja ekonomi industri pengeringan dan penggaraman ikan dan biota perairan lainnya yaitu sebesar $1,1141 \%$ dengan tambahan penyerapan tenaga kerja sebanyak 12.581 orang, sedangkan industri pengolahan dan pengawetan ikan dan biota perairan lainnya hanya meningkat sebesar $0,3086 \%$ dengan tambahan penyerapan tenaga kerja sebanyak 2.832 orang.

\section{KESIMPULAN DAN IMPLIKASI KEBIJAKAN}

\section{Kesimpulan}

Peningkatan konsumsi produk perikanan sebesar $11,54 \%$ di tingkat rumah tangga berdampak positif terhadap kinerja output, pendapatan rumah tangga dan penyerapan tenaga kerja seluruh sektor dalam perekonomian Indonesia masing-masing sebesar $5,24 \%$ dalam bentuk peningkatan output perekonomian sebesar Rp. 10.018.185.000, pendapatan rumah tangga sebesar Rp. 1.166 .463 juta dan penyerapan tenaga kerja sebanyak 151.133 orang. Dampak positif terhadap sektor perikanan sendiri adalah sebesar $5,18 \%$, dalam bentuk peningkatan output sebesar Rp. 9.884.302.000, pendapatan rumah tangga sebesar Rp. 1.145.366.000 dan penyerapan tenaga kerja sebanyak 148.765 orang. Spillover dampak mencapai sebesar 0,06\% yang akan yang dinikmati oleh sektor lain di luar sektor perikanan dalam bentuk peningkatan output perekonomian sebesar Rp. 133.833.000, pendapatan rumah tangga sebesar Rp. 21.097.000 dan penyerapan tenaga kerja sebanyak 2.368 orang.

Dampak parsial sektor perikanan, secara relatif dampak positif terhadap perikanan primer dari peningkatan konsumsi rumah tangga produk perikanan $(3,75 \%)$ lebih besar dibandingkan dengan perikanan sekunder $(1,42 \%)$. Pada perikanan primer, dampak positif secara relatif didominasi oleh peningkatan kinerja output perekonomian perikanan darat yaitu sebesar $2,52 \%$, sedangkan perikanan laut hanya meningkat sebesar 1,23\%. Pada perikanan sekunder, dampak positif secara relatif didominasi oleh peningkatan kinerja output perekonomian industri pengeringan dan penggaraman ikan dan biota perairan lainnya yaitu sebesar $1,11 \%$, sedangkan industri pengolahan dan pengawetan ikan dan biota perairan lainnya hanya meningkat sebesar $0,31 \%$. 
Secara absolut, dampak pada perikanan darat dalam bentuk peningkatan output perekonomian sebesar Rp. 3.190.192 juta, pendapatan rumah tangga sebesar $\mathrm{Rp}$. 502.298 juta dan penyerapan tenaga kerja sebanyak 29.567 orang; sedangkan pada perikanan laut dalam bentuk peningkatan output perekonomian sebesar Rp. 2.059.759 juta, pendapatan rumah tangga sebesar Rp. 338.607 juta dan penyerapan tenaga kerja sebanyak 103.785 orang. Sementara pada industri pengeringan dan penggaraman ikan dan biota perairan lainnya dampak dalam bentuk peningkatan output perekonomian sebesar Rp.3.782.728 juta, pendapatan rumah tangga sebesar Rp. 258.167 juta dan penyerapan tenaga kerja sebanyak 12.581 orang; sedangkan pada industri pengolahan dan pengawetan ikan dan biota perairan lainnya dalam bentuk peningkatan output perekonomian sebesar Rp. 851.624 juta, pendapatan rumah tangga sebesar Rp. 46.293 juta dan penyerapan tenaga kerja sebanyak 2.832 orang.

\section{Implikasi Kebijakan}

Mengingat bahwa peningkatan konsumsi rumah tangga pada produk hasil perikanan memberikan dampak positif yang tergolong besar dalam peningkatan output perekonomian, pendapatan rumah tangga dan penyerapan tenaga kerja, tidak saja bagi sektor perikanan tetapi juga bagi seluruh sektor dalam perekonomian secara keseluruhan, maka sebaiknya semua kebijakan dan program pemerintah terkait dengan peningkatan konsumsi ikan dapat diimplementasi dengan lebih sungguhsungguh dan konsisten. Terlebih lagi bila hal tersebut dikaitkan dengan upaya pemerintah untuk mengatasi permasalahan pangan melalui program ketahanan pangan khususnya dari sumber hewani ikan, dan melalui kebijakan dan program mengefektifkan peran pasar dalam negeri produk perikanan. Upaya tersebut dinilai strategis karena memiliki potensi membantu bangsa ini untuk keluar dari kesulitan perekonomian akibat tekanan krisis keuangan global. Upaya tersebut seyogyanya dipandang sebagai langkah penting yang harus didukung secara politis oleh segenap kekuatan bangsa, mulai dari tingkat masyarakat, pemerintah dan pelaku usaha.

\section{DAFTAR PUSTAKA}

Badan Pusat Statistik (BPS). 2007. Tabel Input-Output Indonesia 2005. Jilid I, II dan III. Badan Pusat Statistik. Jakarta.

Departemen Kelautan dan Perikanan (DKP). 2005 . Pelaksanaan Pembangunan Kelautan dan Perikanan dalam Satu Tahun Kabinet Indonesia Bersatu. Departemen Kelautan dan Perikanan. Jakarta. Hal. 16.

Departemen Kelautan dan Perikanan (DKP). $2005^{\mathrm{b}}$. Rencana Strategis Pembangunan Kelautan dan Perikanan Tahun 20052009. Departemen Kelautan dan Perikanan. Jakarta. 43 halaman.

Departemen Kelautan dan Perikanan (DKP). 2006. Ikan Menyehatkan dan Mencerdaskan Bangsa. Email: pusinfoyanmas@dkp.go.id. Website: www.dkp.go.id. 02-11-2006.

Lahr, M.L., and Dietzenbacher, E. 2001. Input-Analysis: Frontiers and Extensions. Palgave Publisher. Tottenham Court Road, London. P.: 451476.

Mangiri, K. 2000. Perencanan Terpadu Pembangunan ekonomi Daerah Otonom (Pendekatan Model Input-Output). Center for Statistical Services (CSS), Badan Pusat Statistik. Jakarta. Hal.: 139-154.

Miller, R. and Blair, P. 1985. Input-Output Analysis: Foundation and Extensions. Prentice-Hall, Inc. Englewood Cliffs, New Jersey 07632. 464 p.

Muhammad, M. 2003. Indeks Pembangunan Manusia di Indonesia. Koran Tempo. Jakarta. 
Nazara, S. 2007. Analisis Input-output, Lembaga Penerbit Fakultas Ekonomi. Universitas Indonesia.

Perserikatan Bangsa-Bangsa (PBB). 1988. Studi dalam Metode: Tabel Input-Output dan Analisis. Seri F. No. 14. Rev.1 Penerjemah: Kramadibrata, S. dan Swasono, S.E. Penerbit Universitas Indonesia. Jakarta. 265 halaman.
Todaro, M.P. and Smith, S.C. 2009. Economic Development. Tenth Edition. Pearson Addison Wesley. Boston, San Francisco, Ne York, London, Toronto, Sydney, Tokyo, Sinagpore, Madrid, Mexico City, Munish, Paris, Cape Town, Hongkong, Monreal. $861 \mathrm{p}$.

United National Development Program UNDP. 2004. Human Development Report 2004, UNDP, 2004. 